\section{Death by maladministration: An important category of patient mortality}

To the Editor: South Africa (SA) has witnessed regular protest actions in recent years. These involve major political issues including quality education, service delivery, state capture, and other crucial matters. Despite their large contribution to the national burden of disease, including morbidity and mortality, mental health issues have received much less attention from the public and from the press. And the fate of the most severely impacted, such as those with intellectual disability, appears to be of particularly little interest.

Yet the quality of life of those who are the most vulnerable and voiceless in society often serves as the proverbial canary in the coal mine. Disregard for such individuals is a marker of deep dysfunction in health systems. This has been tragically illustrated through the recent debacle at the Gauteng Department of Health, where administrators demanded the discharge of around 2000 patients with mental illness from the Life Esidimeni facility, leading to the death of at least $94 .{ }^{[1]}$

If we are to learn one lesson from the international experience of deinstitutionalisation over the last 50 years, it is that it should never be pursued as a cost-saving strategy. The funds should always follow the patients into the community. Well-resourced community-based mental health services can provide high-quality care for people living with mental illness, within a human rights framework. Indeed, this approach is strongly endorsed by the World Health Organization. ${ }^{[2]}$ In effect, administrative decisions which override such considerations constitute an important category of patient morbidity and even mortality.

Sustainable development, so sorely needed by our country, is crucially dependent on functional health systems. ${ }^{[3]}$ In the case of HIV, death by maladministration was exemplified in the failure to roll out antiretrovirals, which severely impacted our economic growth. Analogously, deinstitutionalisation of psychiatric services without adequate community care has previously been proposed locally, but fails to provide health or save funds over the long term. ${ }^{[4]}$ Not only is there no health without mental health, ${ }^{[5-8]}$ but arguably there is no sustainable development without mental health; the data continuously indicate that it is less expensive for countries to treat mental illness than to ignore it. . $^{[7]}$

We are heartened that health professionals (including the Society of Psychiatrists of SA) and civil society (including the SA Depression and Anxiety Support Group, and the SA Federation of Mental Health) joined to vigorously oppose the Gauteng Department of Health, and by the independence demonstrated by both the courts and the Health Ombud on this matter. We call for immediate action to implement the National Mental Health Policy Framework and Strategic Plan (2013 - 2020) in provinces, and for adequate community-based care for people living with mental illness. ${ }^{[8]}$

\section{J Stein}

Department of Psychiatry and Mental Health, Medical Research Council Unit on Risk \& Resilience in Mental Disorders, University of Cape Town, Cape Town, South Africa dan.stein@uct.ac.za

\section{Chambers}

South African Depression and Anxiety Support Group (SADAG), Johannesburg, South Africa

\section{Daniels}

Cape Mental Health, Cape Town, South Africa

\section{B Patel, C Sunkel}

South African Federation of Mental Health, Johannesburg, South Africa

\section{J White}

School of Public Health, Faculty of Health Sciences, University of the Witwatersrand, Johannesburg, South Africa

\section{Z Wilson}

South African Depression and Anxiety Support Group (SADAG), Johannesburg, South Africa

\section{Lund}

Department of Psychiatry and Mental Health, Medical Research Council Unit on Risk \& Resilience in Mental Disorders, University of Cape Town, Cape Town, South Africa

1. Makgoba M. Report into the 'Circumstances Surrounding the Deaths of Mentally Ill Patients: Gauten Province.' 2017:60. http://www.ohsc.org.za/images/documents/FINALREPORT.pdf (accessed 1 February 2017).

2. World Health Organization. Organization of Services for Mental Health. Mental Health Policy and Service Guidance Package. Geneva: WHO, 2003.

. Izutsu T, Tsutsumi A, Minas H, et al. Mental health and wellbeing in the Sustainable Development Goals. Lancet Psychiatry 2015;2(12):1052-1054. https//doi.org/10.1016/S2215-0366(15)00457-5

Stein DI, Allwood C, Emsley RA. Community care of psychiatric disorders in South Africa - lessons from research on deinstitutionalisation. S Afr Med J 1999;89(9):942-943.

from research on deinstitutionalisation. S Alt Med 1999;89(9):942-943. Prince M, Patel V, Saxena S, et al. No health wi
https://doi.org/10.1016/S0140-6736(07)61238-0

https://doi.org/10.1016/S0140-6736(07)61238-0
Lund C, Stein DJ, Corrigall J, et al. Mental health is integral to public health: A call to scale up evidence. Lund C, Stein DJ, Corrigall J, et al. Mental health is integral to public health: A call to scate
based services and develop mental health research. S Afr Med J 2008;98(6):444-446.

7. Lund C, Myer L, Stein DJ, Williams DR, Flisher AJ. Mental illness and lost income among adult South Africans. Soc Psychiatry Psychiatr Epidemiol 2013;48(5):845-851. https://doi.org/10.1007/s00127-0120587-5

8. Stein DJ. A new mental health policy for South Africa. S Afr Med J 2014;104(2):115-116. https://doi. org/10.7196/samj.7938

S Afr Med J 2017;107(4):280. DOI:10.7196/SAMJ.2017.v107i4.12389 